\title{
Synthesis of $\mathrm{Er}^{3+}$ and $\mathrm{Er}^{3+}: \mathrm{Yb}^{3+}$ doped sol-gel derived silica glass and studies on their optical properties
}

\author{
DIPANKAR MANDAL, H D BANERJEE*, M L N GOSWAMI ${ }^{\dagger}$ and H N ACHARYA ${ }^{\dagger}$ \\ Materials Science Centre, ${ }^{\dagger}$ Central Research Facility, Optical Fibre Unit, Indian Institute of Technology, \\ Kharagpur 721 302, India
}

MS received 1 March 2004; revised 4 July 2004

\begin{abstract}
Er}^{3+}$ and $\mathrm{Er}^{3+}: \mathrm{Yb}^{3+}$ doped optical quality, crack and bubble free glasses for possible use in making laser material have been prepared successfully through sol-gel route. The thermal and optical, including UV-visible absorption, FTIR etc characterizations were undertaken on the samples. The absorption characteristics of $\mathrm{Er}^{3+}$ doped samples clearly revealed the absorption due to $\mathrm{Er}^{3+}$ ions. On the other hand $\mathrm{Yb}^{3+}: \mathrm{Er}^{3+}$ doped samples showed enhanced absorption due to ${ }^{2} F_{7 / 2} \rightarrow{ }^{2} F_{5 / 2}$ transition. The absorption and emission crosssection for ${ }^{2} F_{7 / 2} \leftrightarrow{ }^{2} F_{5 / 2}$ of $\mathrm{Yb}^{3+}$ were estimated. FTIR absorption spectra have clearly shown the reduction of the absorption peak intensity with heat treatment in the range $3700-2900 \mathrm{~cm}^{-1}$. The $960 \mathrm{~cm}^{-1}$ band also showed progressive decrease in the absorption band peak intensity with heat treatment. The result of the investigations with essential discussions and conclusions have been reported in this paper.
\end{abstract}

Keywords. Sol-gel silica glass; laser material; absorption and emission cross-section.

\section{Introduction}

Sol-gel glasses doped with rare-earth (RE) ions are of interest for various applications including solid state lasers, optical waveguides and fibre amplifiers. The main characteristics of spectroscopic transition involving RE ions are long lifetime of metastable states (ranging from tens of microsec to a few millisec) and narrow absorption and emission lines in the near infrared regions. The most widely used wavelength for amplification and transition of optical signal are around 1.3 and $1.5 \mu \mathrm{m}$. It is observed that as compared to other RE ions, erbium $\left(\mathrm{Er}^{3+}\right)$ is the most suitable for amplification at $1.5 \mu \mathrm{m}$. Besides, $\mathrm{Er}^{3+}$ silica glasses co-doped with ytterbium $\left(\mathrm{Yb}^{3+}\right)$ are chosen for getting better lasing property that can act as a eyesafe laser sources near $1540 \mathrm{~nm}$, which is the range of wavelengths focused on the retina of the human eye (Winburn 1985).

$\mathrm{Er}^{3+}$ emission transition occurs within this wavelength range corresponding to the ${ }^{4} I_{13 / 2} \rightarrow{ }^{4} I_{15 / 2}$ transition. However, $\mathrm{Er}^{3+}$ absorbance itself is too weak to allow direct pumping and so, energy transfers are required. The most efficient ones are given by $\mathrm{Yb}^{3+}$ ions under absorption from the ${ }^{2} F_{7 / 2} \rightarrow{ }^{2} F_{5 / 2}$ transition, followed by energy transfer to the ${ }^{4} I_{11 / 2} \mathrm{Er}^{3+}$ level and fast nonradiative transition to the ${ }^{4} I_{13 / 2}$ level which emits the expected fluorescence. As a matter of fact, $\mathrm{Yb}^{3+}$ concentration has to be optimized to get the highest absorption coefficient.

It is to be mentioned that it is very difficult to prepare REs doped silica glass by the conventional technique in-

*Author for correspondence volving the quenching of an oxide melt due to the high melting temperature of $\mathrm{SiO}_{2}$. But silica based glasses show excellent durability and optical quality. The sol-gel process offers an attractive method for preparing these materials at relatively lower temperature without melting, and it produces an opportunity of having a control over the microstructure and composition of host matrix (Brickner and Scherer 1990). However, high concentration of hydroxyl groups that remain in sol-gel glasses is a disadvantage of the sol-gel method as it decreases the fluorescence efficiencies and shorten luminescent level lifetimes of dopant ions in glasses, adversely affecting optical device performance (Phalippou et al 1984; Berry and King 1989). Techniques leading to the low hydroxyl sol-gel glasses include high temperature treatment in the presence of carbon tetrachloride (Phalippou et al 1984), inclusion of hydrofluoric acid in the initial solution (Pope and Mckenzie 1993) and heat treatment in different atmospheres (oxygen, vacuum, carbon tetrachloride and helium) (Ainslie et al 1988). The other problem associated with sol-gel process is RE ions clustering (Fujiyama et al 1990), leading to concentration quenching of luminescence through cross-relaxation or energy transfer process.

In view of the above, a comprehensive work on the synthesis of $\mathrm{Er}^{3+}$ and $\mathrm{Er}^{3+}: \mathrm{Yb}^{3+}$ doped silica glasses by solgel technique and their optical characterization have been undertaken in our laboratory having the following objectives in mind.

(I) Synthesis and perfection of techniques of synthesis of these class of rare-earth doped glasses by sol-gel technique.

(II) Understanding the actual absorption, energy transfer 
and emission mechanism involved in these materials so as to examine the suitability of these prepared glass for use in making laser material.

Transparent, crack and bubble free glasses were thus prepared reproducibly.

\section{Experimental}

Silica sols containing $1.0 \mathrm{~mol} \% \mathrm{Er}_{2} \mathrm{O}_{3}$ and different mol\% $(0.5,1 \cdot 0,1 \cdot 5) \mathrm{Yb}_{2} \mathrm{O}_{3}$ were prepared using tetraethyl orthosilicate, $\mathrm{ErCl}_{3}, 6 \mathrm{H}_{2} \mathrm{O}, \mathrm{YbCl}_{3}, 6 \mathrm{H}_{2} \mathrm{O}$, deionized water, $\mathrm{HCl}$ and $\mathrm{NH}_{4} \mathrm{OH}$. The chemicals used were all AR (analytical reagent) grade. Calculated amount of dopant salts were poured in TEOS under stirring condition at room temperature. The molar ratio of TEOS $: \mathrm{H}_{2} \mathrm{O}: \mathrm{HCl}$ was $1: 14: 0 \cdot 01$. The $\mathrm{pH}$ of the sols were adjusted to $3 \cdot 5$ by addition of $\mathrm{NH}_{4} \mathrm{OH}$ solution in it. The sols were cast into petri dishes and kept for 10 days for aging at room temperature. They were then dried for three weeks at $55^{\circ} \mathrm{C}$ and finally heat treated at $900^{\circ} \mathrm{C}$ in air.

Transparent, crack and bubble free glasses were thus prepared reproducibly. The absorption spectra of the samples were taken in the wavelength range 300-1100 nm using UV-vis spectrophotometer (Perkin Elmer Instruments, Lambda 25). TGA/DTA analyses were carried out using a Perkin-Elmer Instrument (Pyris Diamond TG/DTA, thermogravimetric/differential thermal analyser). XRD studies were conducted in $\left(15-50^{\circ}\right) 2 \theta$ range using a PW 1710 diffractometer with $\mathrm{CuK}_{\alpha}$ radiation $(\lambda=1.5405 \AA)$. The infrared (IR) spectra were measured with the help of infrared spectrophotometer (Thermo Nicolet, NEXUS 870). All measurements were carried out at room temperature $\left(25^{\circ} \mathrm{C}\right)$.

\section{Results and discussion}

\subsection{Visual characteristic}

All the gel samples were transparent (figure 1). The colour of the gels was found to depend on the dopant ions (bright

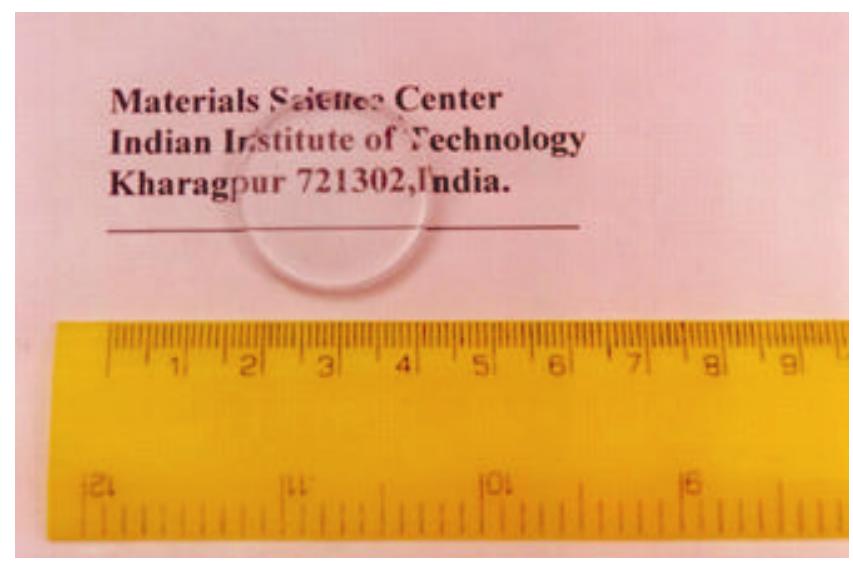

Figure 1. Photograph of a gel sample sintered at $900^{\circ} \mathrm{C}$. pink for Er and comparatively less bright pink for Er-Yb) and was found to deepen with dopant concentrations.

\subsection{Thermal characteristics}

The dried gels when heated above $50^{\circ} \mathrm{C}$, underwent weight loss and consequently shrinkage. Figures 2 and 3 show DTA and TGA curves of $1.0 \mathrm{~mol} \% \mathrm{Er}_{2} \mathrm{O}_{3}$ doped dried gel up to $1200^{\circ} \mathrm{C}$ at a heating rate of $10^{\circ} \mathrm{C} / \mathrm{min}$ in air. An endothermic peak is observed in DTA curve from $50^{\circ} \mathrm{C}$ and $200^{\circ} \mathrm{C}$. The TGA curve shows a $10 \%$ weight loss around this temperature range. The peak associated with the weight loss may be attributed to the escape of absorbed water. The second stage of weight loss as shown in TGA curve occurred due to decomposition and oxidation of organic matters as supported by the appearance of a broad exothermic band at $500^{\circ} \mathrm{C}$ in DTA curve. Beyond $700^{\circ} \mathrm{C}$, the weight loss is small and gradual with further heat treatment (indicated in TGA curve). The weight loss at elevated temperatures is probably due to removal of water during con-

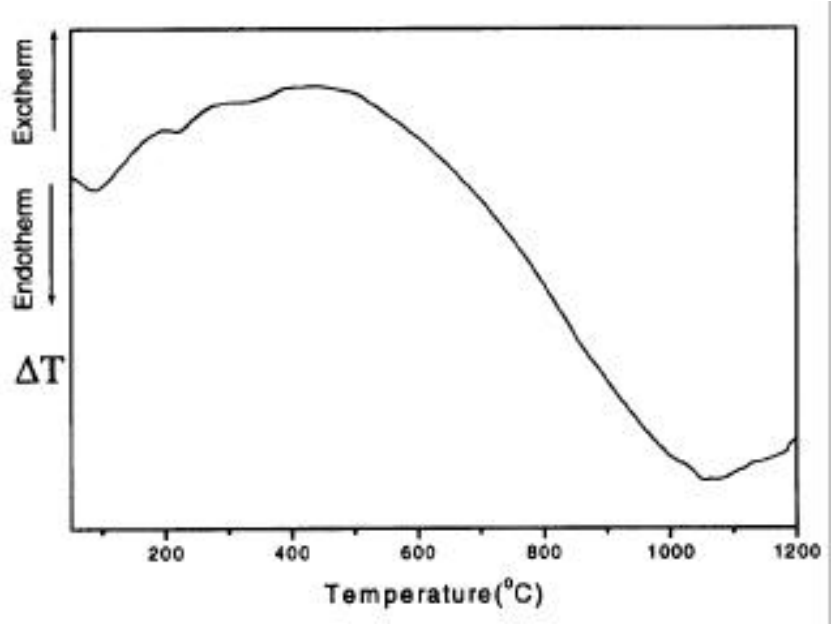

Figure 2. DTA curve for $1.0 \mathrm{~mol} \%$ of $\mathrm{Er}_{2} \mathrm{O}_{3}$ doped silica gel.

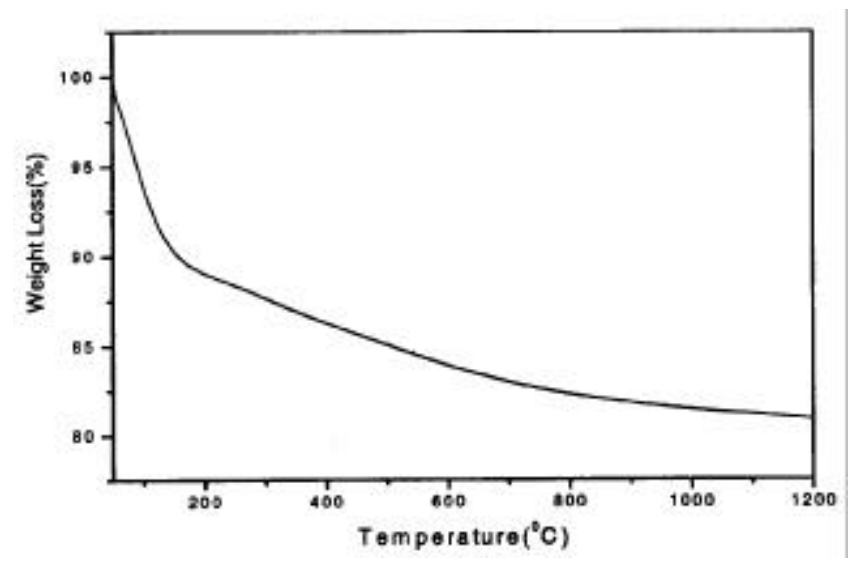

Figure 3. TGA curve for $1.0 \mathrm{~mol} \%$ of $\mathrm{Er}_{2} \mathrm{O}_{3}$ doped silica gel. 
densation. A total weight loss of about $18 \%$ and $19 \%$ are observed for heating up to $1000^{\circ} \mathrm{C}$ and $1200^{\circ} \mathrm{C}$, respectively.

\subsection{Structural analysis}

Figures 4 and 5 show XRD patterns of $1.0 \mathrm{~mol} \% \mathrm{Er}_{2} \mathrm{O}_{3}$ and $1.0 \mathrm{~mol} \% \mathrm{Er}_{2} \mathrm{O}_{3}$ with $1.0 \mathrm{~mol} \% \mathrm{Yb}_{2} \mathrm{O}_{3}$ doped silica gels sintered at $900^{\circ} \mathrm{C}$, respectively. In both the cases, only broad diffraction peaks were observed. The broadness of these peaks indicate amorphous nature of glassy phase. Therefore, it can be concluded that there is no chance of forming crystalline phase up to $900^{\circ} \mathrm{C}$ sintering.

\subsection{Absorption spectra}

Figure 6 shows the absorption spectra (300-1100 nm range) of $1.0 \mathrm{~mol} \% \mathrm{Er}_{2} \mathrm{O}_{3}$ doped silica gels (B) and $1.0 \mathrm{~mol} \%$ $\mathrm{Er}_{2} \mathrm{O}_{3}$ and $0.5 \mathrm{~mol} \% \mathrm{Yb}_{2} \mathrm{O}_{3}$ doped silica gels (A) densified at $900^{\circ} \mathrm{C}$. All the absorption peaks correspond to the atomic transitions of $\mathrm{Er}^{3+}$ ions. In contrast to many excited-state multiplets of $\mathrm{Er}^{3+}$, the $\mathrm{Yb}^{3+}$ ion has only one excited-state multiplet $\left({ }^{2} F_{5 / 2}\right)$, and the respective absorptions from the ${ }^{2} F_{7 / 2}$ ground state multiplet are observed around $976 \mathrm{~nm}$. The spectra is similar to the one reported earlier (Ainslie et al 1988) for $\mathrm{Er}^{3+}$ doped sample. The absorption cross-section of ${ }^{2} F_{7 / 2} \rightarrow{ }^{2} F_{5 / 2}$ is more than an order of magnitude greater than for the $\mathrm{Er}^{3+},{ }^{4} I_{15 / 2} \rightarrow{ }^{4} I_{11 / 2}$ absorption in this wavelength range. The different transitions of $\mathrm{Er}^{3+}$ from the ${ }^{4} I_{15 / 2}$ ground state to excited states are shown in table 1 .

\subsection{Absorption $\left(\sigma_{\mathrm{ab}}(\lambda)\right)$ and emission $\left(\sigma_{\mathrm{emi}}(\lambda)\right)$ cross-sections}

From the Lambert-Beer dependency, the absorption cross-section of the ${ }^{2} F_{7 / 2} \rightarrow{ }^{2} F_{5 / 2}$ transition of $\mathrm{Yb}^{3+}$ ions have

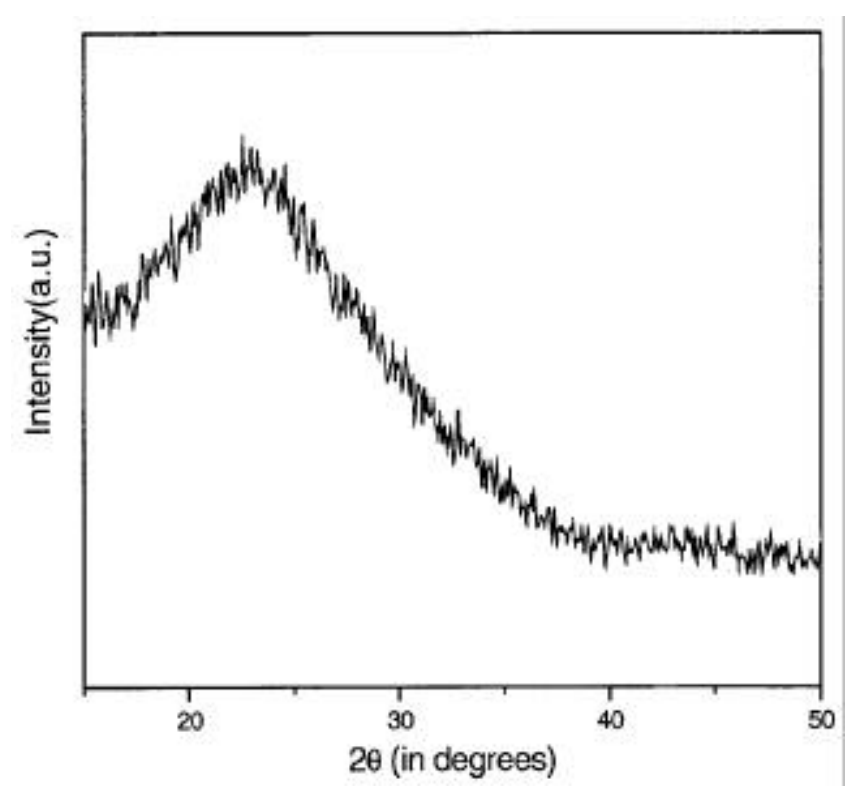

Figure 4. XRD pattern for $1.0 \mathrm{~mol} \%$ of $\mathrm{Er}_{2} \mathrm{O}_{3}$ doped gel sintered at $900^{\circ} \mathrm{C}$. been determined from the absorption spectra using the formula

$$
\sigma_{\mathrm{ab}}(\lambda)=2 \cdot 303 \log \left(I_{0} / I\right) /(N 1),
$$

where $\log \left(I_{0} / I\right)$ is absorbance, 1 the sample thickness, and $N$ the $\mathrm{Yb}^{3+}$ ion (ions $/ \mathrm{cm}^{3}$ ) concentration.

There are a number of ways (MaCumber 1964; Koechner 1986; Martin and Milam 1982) by which emission crosssections can be determined. Here the emission cross-

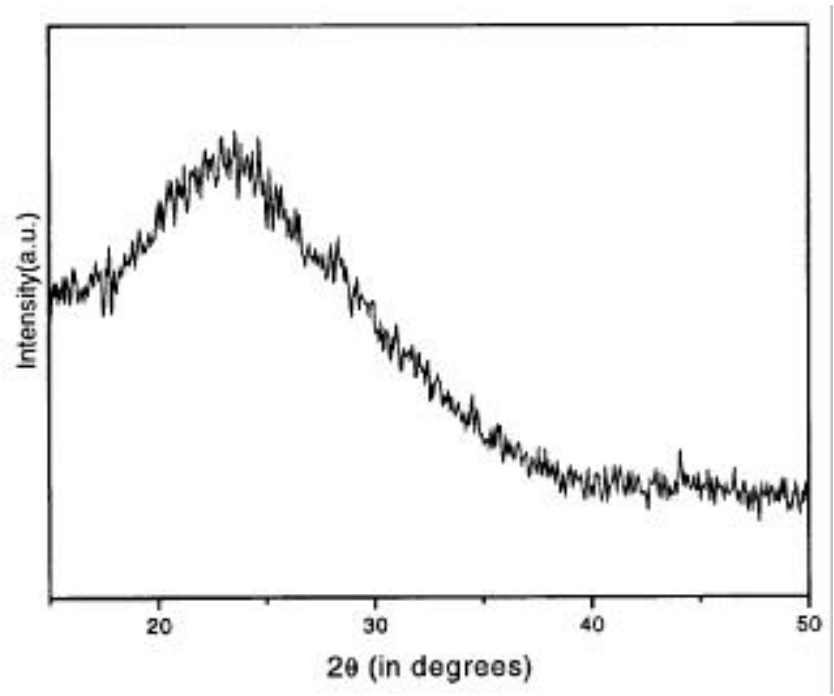

Figure 5. XRD pattern for $1.0 \mathrm{~mol} \%$ of $\mathrm{Yb}_{2} \mathrm{O}_{3}$ and $1.0 \mathrm{~mol} \%$ of $\mathrm{Er}_{2} \mathrm{O}_{3}$ doped silica gel sintered at $900^{\circ} \mathrm{C}$.

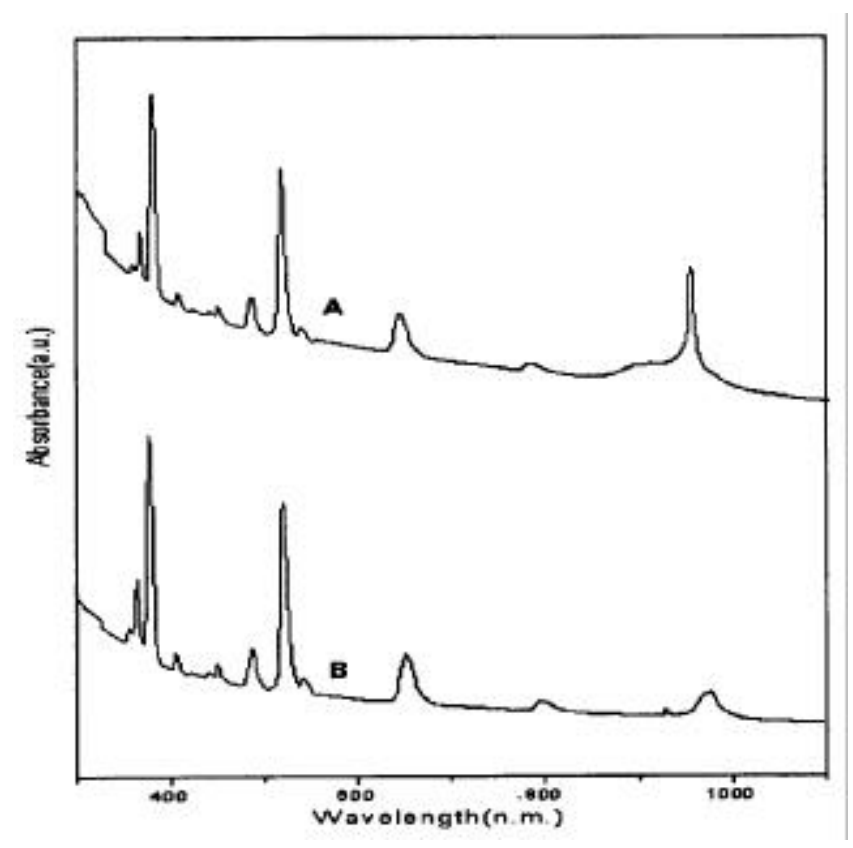

Figure 6. The UV-vis absorption spectra of (A) $0.5 \mathrm{~mol} \%$ $\mathrm{Yb}_{2} \mathrm{O}_{3}$ and $1.0 \mathrm{~mol} \% \mathrm{Er}_{2} \mathrm{O}_{3}$ doped silica gels sintered at $900^{\circ} \mathrm{C}$, and (B) $1.0 \mathrm{~mol} \% \mathrm{Er}_{2} \mathrm{O}_{3}$ doped silica gel heated at $900^{\circ} \mathrm{C}$. 
section is calculated using MaCumber (1964) theory. The absorption and emission cross-section are related as

$$
\sigma_{\mathrm{emi}}(\lambda)=\sigma_{\mathrm{ab}}(\lambda) \exp [(E-h v) / k T],
$$

where $v$ is the phonon frequency, $E$ the net free energy required to excite one $\mathrm{Yb}^{3+}$ from ${ }^{2} F_{7 / 2}$ to ${ }^{2} F_{5 / 2}$ state at temperature $T, h$ the Planck's constant, and $k$ the Boltzmann constant. Figures 7-9 illustrate the calculated absorption and emission cross-sections for the ${ }^{2} F_{7 / 2} \rightarrow{ }^{2} F_{5 / 2}$ transition of $\mathrm{Yb}^{3+}$ ions in silicate glasses. The calculated absorption and emission cross-section values of $\sigma_{\mathrm{ab}}(\lambda)$ and $\sigma_{\mathrm{emi}}(\lambda)$ are shown in table 2 (also seen in figures 7-9). The values of cross-sections are larger than the previously reported fluoride glasses (Weber et al 1983) and silicate glass (Allain et al 1993).

The most important laser parameter, $\beta_{\min }$, is defined as the minimum fraction of $\mathrm{Yb}^{3+}$ ions that must be excited to balance the gain exactly with the ground state absorption at laser wavelength, $\lambda_{0}$. The parameter, $\beta_{\min }$, is of crucial importance for quasi four-level systems such as in $\mathrm{Yb}^{3+}$ doped glasses. The value of $\beta_{\min }$ is simply given by (Deloach et al 1994)

$$
\beta_{\text {min }}=\frac{\sigma_{\mathrm{ab}}\left(\lambda_{0}\right)}{\sigma_{\mathrm{emi}}\left(\lambda_{0}\right)+\sigma_{\mathrm{ab}}\left(\lambda_{0}\right)},
$$

when $\beta_{\text {min }}$ fraction of $\mathrm{Yb}^{3+}$ population is excited, the upward and downward transition rates are equal, and the

Table 1. Absorption band positions of $\mathrm{Er}^{3+}$ ions in the wavelength range $300-1100 \mathrm{~nm}$.

\begin{tabular}{lc}
\hline $\begin{array}{l}\text { Level transition from the } \\
\text { ground state, }{ }^{4} I_{15 / 2} \text { to }\end{array}$ & $\begin{array}{c}\text { Wavelength } \\
\text { (nm) }\end{array}$ \\
\hline${ }^{2} K_{15 / 2}$ & 363 \\
${ }^{4} G_{11 / 2}$ & 377 \\
${ }^{2} H_{9 / 2}$ & 405 \\
${ }^{4} F_{3 / 2}$ & 451 \\
${ }^{4} F_{7 / 2}$ & 489 \\
${ }^{2} H_{11 / 2}$ & 519 \\
${ }^{4} S_{3 / 2}$ & 543 \\
${ }^{4} F_{9 / 2}$ & 653 \\
${ }^{4} I_{9 / 2}$ & 800 \\
${ }^{4} I_{11 / 2}$ & $976 *$ \\
\hline
\end{tabular}

*Here level transition from the ground state ${ }^{2} F_{7 / 2}$ to excited ${ }^{2} F_{5 / 2}$ also exists by the influence of $\mathrm{Yb}^{3+}$ ions.

Table 2. Absorption and emission cross-sections and laser performance parameters for $\mathrm{Er}: \mathrm{Yb}$ doped silica glasses with different compositions.

\begin{tabular}{lccc}
\hline Sample composition $(\mathrm{mol} \%)$ & $\sigma_{\mathrm{ab}}\left(\mathrm{pm}^{2}\right)$ & $\sigma_{\mathrm{emi}}\left(\mathrm{pm}^{2}\right)$ & $\beta_{\text {min }}$ \\
\hline $1 \cdot 0 \mathrm{Er}_{2} \mathrm{O}_{3} \cdot 0 \cdot 5 \mathrm{Yb}_{2} \mathrm{O}_{3} \cdot 98 \cdot 5 \mathrm{SiO}_{2}$ & $0 \cdot 79$ & $0 \cdot 73$ & 0.51 \\
$1 \cdot 0 \mathrm{Er}_{2} \mathrm{O}_{3} \cdot 1 \cdot 0 \mathrm{Yb}_{2} \mathrm{O}_{3} \cdot 98 \cdot 0 \mathrm{SiO}_{2}$ & $0 \cdot 83$ & 0.92 & 0.47 \\
$1 \cdot 0 \mathrm{Er}_{2} \mathrm{O}_{3} \cdot 1 \cdot 5 \mathrm{Yb}_{2} \mathrm{O}_{3} \cdot 97 \cdot 5 \mathrm{SiO}_{2}$ & 0.63 & $0 \cdot 70$ & 0.47 \\
\hline
\end{tabular}

glass essentially becomes transparent at $\lambda_{0}$, such that there is neither gain nor loss for a weak laser probe beam.

The laser performance parameter, $\beta_{\min }$, for this study has been calculated and is shown in table 2 . The $\beta_{\text {min }}$ parameter addresses the effect of the resonant absorption loss of $\mathrm{Yb}^{3+}$ at $\lambda_{0}$. Here favourable spectroscopic parameters include a large emission cross-section and absorption cross-sections for corresponding laser transition.

\subsection{IR spectra}

The infrared spectra $\left(4000-400 \mathrm{~cm}^{-1}\right)$ of $1.0 \mathrm{~mol} \% \mathrm{Er}_{2} \mathrm{O}_{3}$ and $1.0 \mathrm{~mol} \% \mathrm{Yb}_{2} \mathrm{O}_{3}$ doped silica gels dried at $55^{\circ} \mathrm{C}$ and sintered at $900^{\circ} \mathrm{C}$ are shown in figures 10 and 11 , respec-

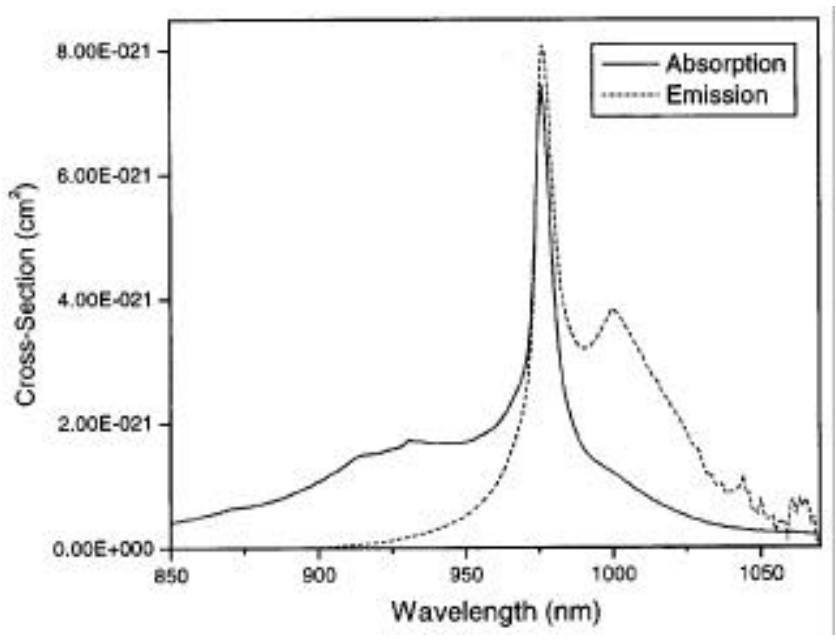

Figure 7. The absorption and emission cross-section spectra for $1.0 \mathrm{~mol} \%$ of $\mathrm{Er}_{2} \mathrm{O}_{3}$ and $0.5 \mathrm{~mol} \%$ of $\mathrm{Yb}_{2} \mathrm{O}_{3}$ doped silica gels sintered at $900^{\circ} \mathrm{C}$.

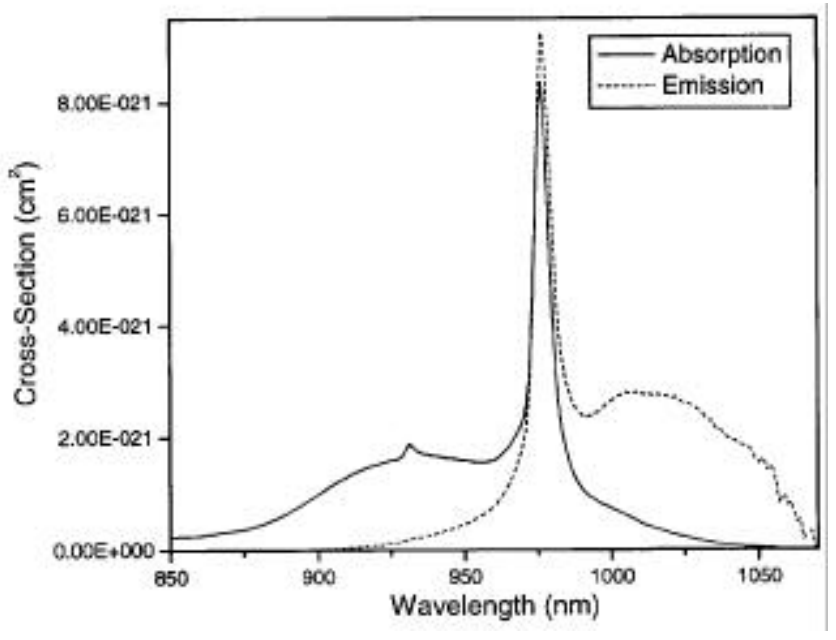

Figure 8. The absorption and emission cross-section spectra for $1.0 \mathrm{~mol} \%$ of $\mathrm{Er}_{2} \mathrm{O}_{3}$ and $1.0 \mathrm{~mol} \%$ of $\mathrm{Yb}_{2} \mathrm{O}_{3}$ doped silica gels sintered at $900^{\circ} \mathrm{C}$. 


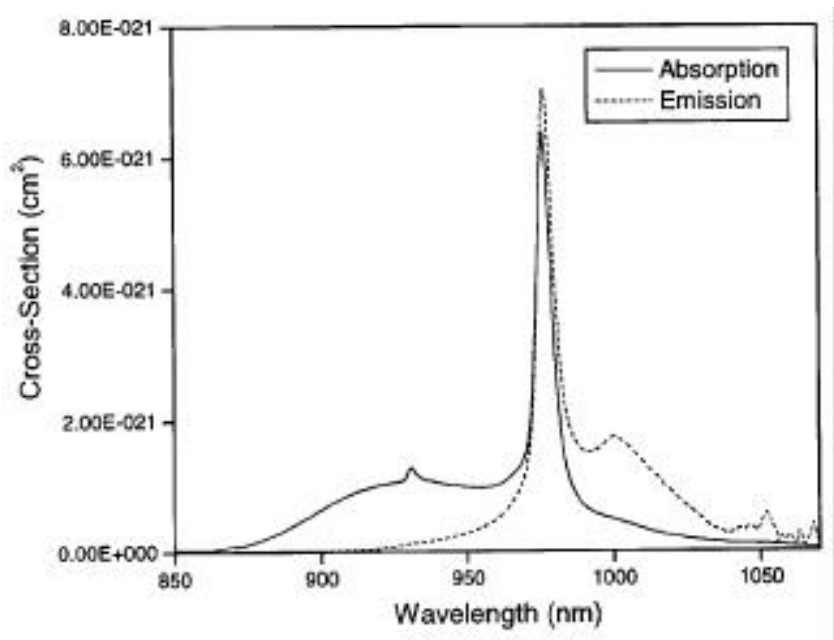

Figure 9. The absorption and emission cross-section spectra for $1.0 \mathrm{~mol} \%$ of $\mathrm{Er}_{2} \mathrm{O}_{3}$ and $1.5 \mathrm{~mol} \%$ of $\mathrm{Yb}_{2} \mathrm{O}_{3}$ doped silica gels sintered at $900^{\circ} \mathrm{C}$.

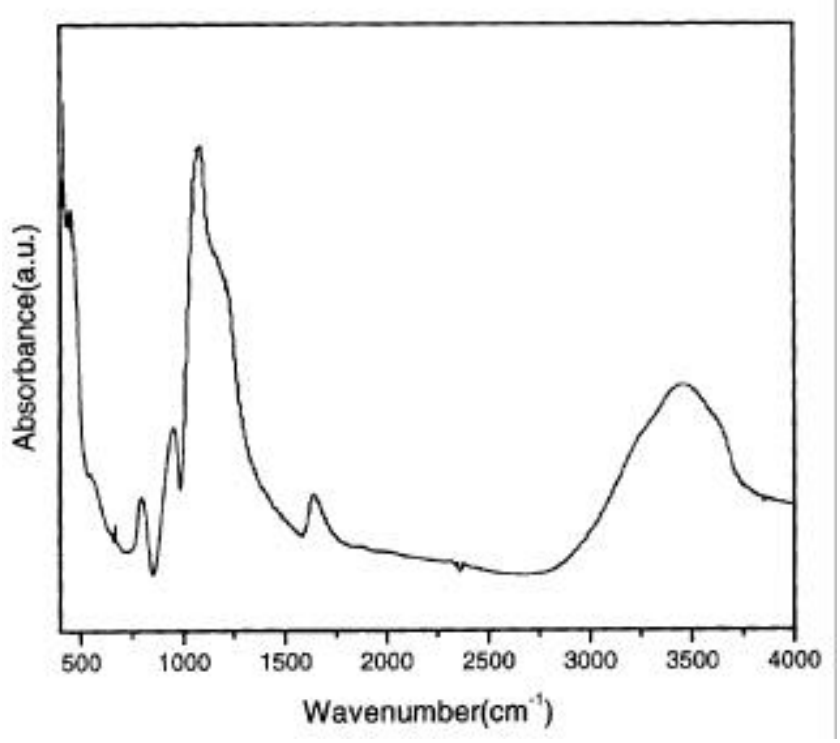

Figure 10. FTIR spectra of $1.0 \mathrm{~mol} \% \mathrm{Yb}_{2} \mathrm{O}_{3}$ and $1.0 \mathrm{~mol} \%$ $\mathrm{Er}_{2} \mathrm{O}_{3}$ doped silica gels dried at $55^{\circ} \mathrm{C}$.

tively. The figures show a broad absorbance ranging from $3700-2900 \mathrm{~cm}^{-1}$. This is attributed to the presence of $\mathrm{Si}-$ $\mathrm{OH}$ stretching vibration and absorbed water. The area under the curve and intensity, which are highest for gel, dried at $55^{\circ} \mathrm{C}$, progressively diminishes with the heat treatment. This indicates the decrease in absorbed water in the gel structure. The peak at $1630 \mathrm{~cm}^{-1}$ caused by the $-\mathrm{OH}$ bending vibration (Herzberg 1985) also behaves similarly showing escape of water from the structure of the gels. The $960 \mathrm{~cm}^{-1}$ band induced by the $\mathrm{Si}-\mathrm{O}$ asymmetric stretching vibration progressively gets weakened with rise of temperature (during heat treatment) suggesting gradual increase in strength of the silica network. At high temperature $\left(\sim 800^{\circ} \mathrm{C}\right)$, the spectra resemble that of fused silica

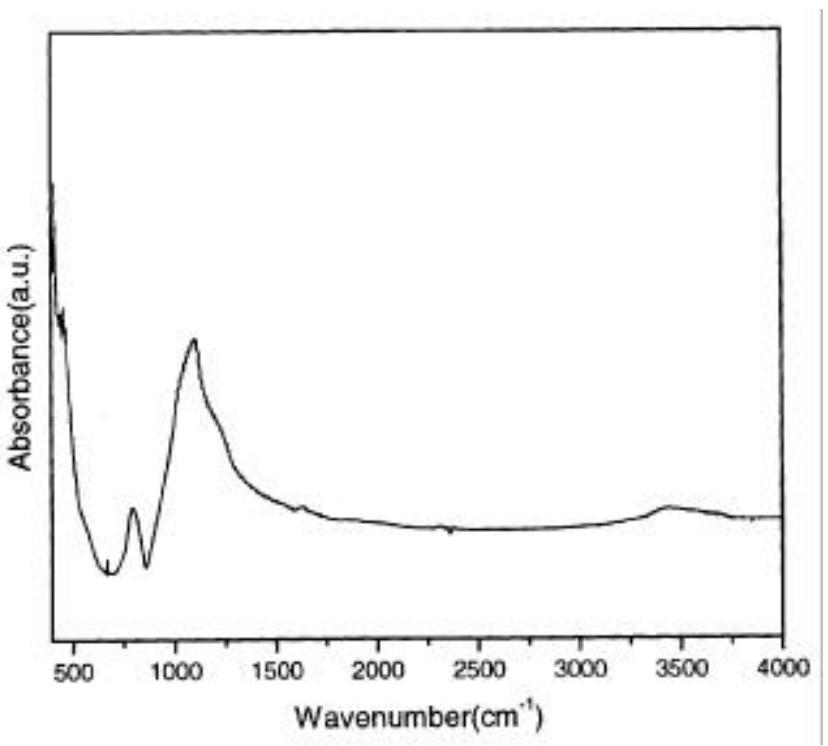

Figure 11. FTIR spectra of $1.0 \mathrm{~mol} \% \quad \mathrm{Yb}_{2} \mathrm{O}_{3}$ and $1.0 \mathrm{~mol} \%$ $\mathrm{Er}_{2} \mathrm{O}_{3}$ doped silica gels sintered at $900^{\circ} \mathrm{C}$.

glass (Ocana et al 1989). The absorption peaks are assigned to the $\mathrm{Si}-\mathrm{O}$ asymmetric stretching vibration $\left(1200 \mathrm{~cm}^{-1}\right)$ and the vibration of siloxane chains $\left(1080 \mathrm{~cm}^{-1}\right)$. The peak at $810 \mathrm{~cm}^{-1}$ is due to $\mathrm{Si}-\mathrm{O}-\mathrm{Si}$ bending mode while that at $465 \mathrm{~cm}^{-1}$ is due to $\mathrm{O}-\mathrm{Si}-\mathrm{O}$ bending mode (Bechstedtc and Hubner 1987).

It is seen from figure 11 that, with the rise in sintering temperature, the band $3700-2900 \mathrm{~cm}^{-1}$ shifts towards higher frequency region and the area under the band decreases. This is likely to be due to the removal of ethyl groups during heating. The absorbance due to $\mathrm{C}-\mathrm{O}$ stretching vibration at $1050 \mathrm{~cm}^{-1}$ too is obscured by the strong bands due to $\mathrm{Si}-\mathrm{O}$ vibration. Thus, complete removal of carbon from the gel-derived glass, on pyrolysis, could not be conclusively proved.

\section{Conclusions}

The possibility of synthesizing optical quality crack and bubble free silica glasses doped with rare-earth ions $\left(\mathrm{Er}^{3+}\right.$, $\left.\mathrm{Er}^{3+}: \mathrm{Yb}^{3+}\right)$ have been demonstrated. The thermal and optical characterization on some typical samples have been undertaken. The transitions responsible for absorption and emission have been identified. The increased absorption and emission cross-section at $975 \mathrm{~nm}$ indicates better luminescence emission in near infrared region for its possible use as a laser material.

\section{References}

Ainslie B J, Craig S P and Davey S T 1988 J. Lightwave Tech. 6287

Allain J Y, Monerie M and Poignant H 1993 Electron. Lett. 29309 Bechstedtc F and Hubner K 1987 J. Non-Cryst. Solids 93125 
Berry A J and King T A 1989 J. Phys. D22 1419

Brickner C J and Scherer G W 1990 Sol-gel science (Boston: Academic Press)

Deloach L D, Payne S A, Smith L K, Kway W L and Krupke W F 1994 J. Opt. Soc. Am. B11 269

Fujiyama T, Hori M and Sasaki M 1990 J. Non-Cryst. Solids 121273

Herzberg G 1985 Infrared and Raman spectra of polyatomic molecules (New York: Van Nostrand) p. 280

Koechner W 1986 Solid state laser engineering (New York: Springer) p. 17

MaCumber D E 1964 Phys. Rev. A134 299; A136 954
Martin W E and Milam D 1982 IEEE J. Quantum Electron. QE181155

Ocana M, Frones V and Serna C J 1989 J. Non-Cryst. Solids 170 187

Phalippou J, Woignier T and Zarzycki J 1984 Ultrastructure processing of ceramics, glasses and composites (eds) L L Hench and D R Ulrich (New York: Wiley) p. 70

Pope E J A and Mackenzie J D 1993 J. Am. Ceram. Soc. 76 1325

Weber M J, Lynch J E, Blackburn D H and Cronin D J 1983 IEEE J. Quantum Electron. QE-19 1600

Winburn D C 1985 Practical laser safety (New York: Dekker) 